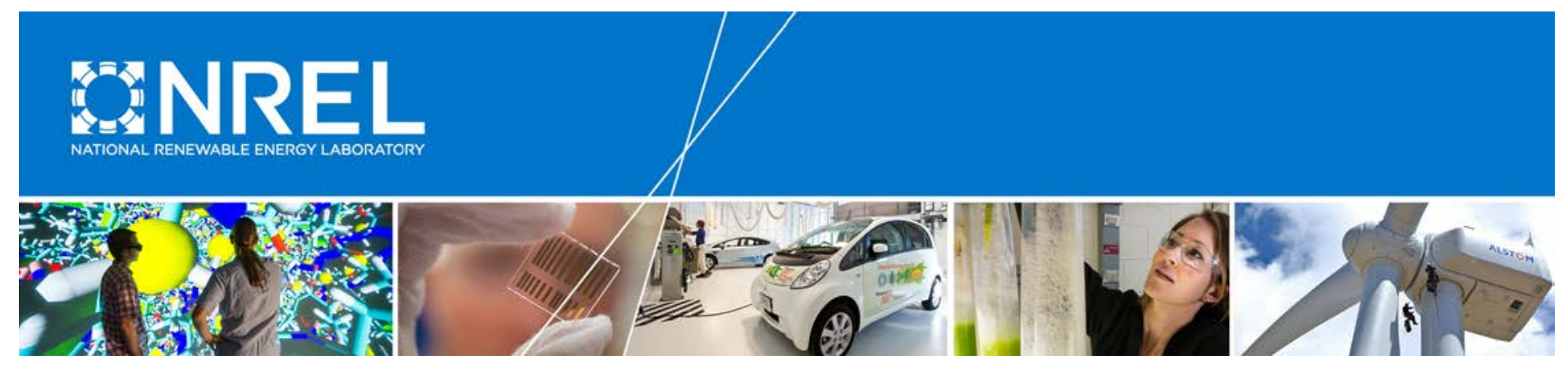

\title{
Analysis of a Wave-Powered, Reverse-Osmosis System and Its Economic Availability in the United States
}

\section{Preprint}

Yi-Hsiang Yu and Dale Jenne

National Renewable Energy Laboratory

Presented at the American Society of Mechanical Engineers' International Conference on Ocean, Offshore and Arctic Engineering (OMAE 2017)

Trondheim, Norway

June 25-30, 2017

NREL is a national laboratory of the U.S. Department of Energy Office of Energy Efficiency \& Renewable Energy Operated by the Alliance for Sustainable Energy, LLC

This report is available at no cost from the National Renewable Energy Laboratory (NREL) at www.nrel.gov/publications.

Conference Paper

NREL/CP-5000-67973

August 2017

Contract No. DE-AC36-08G028308 


\section{NOTICE}

The submitted manuscript has been offered by an employee of the Alliance for Sustainable Energy, LLC (Alliance), a contractor of the US Government under Contract No. DE-AC36-08GO28308. Accordingly, the US Government and Alliance retain a nonexclusive royalty-free license to publish or reproduce the published form of this contribution, or allow others to do so, for US Government purposes.

This report was prepared as an account of work sponsored by an agency of the United States government. Neither the United States government nor any agency thereof, nor any of their employees, makes any warranty, express or implied, or assumes any legal liability or responsibility for the accuracy, completeness, or usefulness of any information, apparatus, product, or process disclosed, or represents that its use would not infringe privately owned rights. Reference herein to any specific commercial product, process, or service by trade name, trademark, manufacturer, or otherwise does not necessarily constitute or imply its endorsement, recommendation, or favoring by the United States government or any agency thereof. The views and opinions of authors expressed herein do not necessarily state or reflect those of the United States government or any agency thereof.

This report is available at no cost from the National Renewable Energy Laboratory (NREL) at www.nrel.gov/publications.

Available electronically at SciTech Connect http:/www.osti.gov/scitech

Available for a processing fee to U.S. Department of Energy and its contractors, in paper, from:

U.S. Department of Energy

Office of Scientific and Technical Information

P.O. Box 62

Oak Ridge, TN 37831-0062

OSTI http://www.osti.gov

Phone: 865.576.8401

Fax: 865.576.5728

Email: reports@osti.gov

Available for sale to the public, in paper, from:

U.S. Department of Commerce

National Technical Information Service

5301 Shawnee Road

Alexandria, VA 22312

NTIS http://www.ntis.gov

Phone: 800.553 .6847 or 703.605 .6000

Fax: 703.605.6900

Email: orders@ntis.gov 


\section{OMAE2017-62136}

\section{ANALYSIS OF A WAVE-POWERED, REVERSE-OSMOSIS SYSTEM AND ITS ECONOMIC AVAILABILITY IN THE UNITED STATES}

\author{
Yi-Hsiang Yu* \\ National Renewable Energy Laboratory \\ Golden, CO, USA \\ Email: yi-hsiang.yu@nrel.gov
}

\author{
Dale Jenne \\ National Renewable Energy Laboratory \\ Golden, CO, USA \\ Email: dale.jenne@nrel.gov
}

\section{ABSTRACT}

A wave energy converter (WEC) system has the potential to convert the wave energy resource directly into the highpressure flow that is needed by the desalination system to permeate saltwater through the reverse-osmosis membrane to generate clean water. In this study, a wave-to-water numerical model was developed to investigate the potential use of a wavepowered desalination system (WPDS) for water production in the United States. The model was developed by coupling a time-domain radiation-and-diffraction-method-based numerical tool (WEC-Sim) for predicting the hydrodynamic performance of WECs with a solution-diffusion model that was used to simulate the reverse-osmosis process. To evaluate the feasibility of the WPDS, the wave-to-water numerical model was applied to simulate a desalination system that used an oscillating surge WEC device to pump seawater through the system. The annual water production was estimated based on the wave resource at a reference site on the coast of northern California to investigate the potential cost of water in that area, where the cost of water and electricity is high compared to other regions. In the scenario evaluated, for a 100-unit utility-scale electricity-producing array, the estimated levelized cost of energy for these WECs is about 3-6 times the U.S.'s current, unsubsidized electricity rates. However, with clean water as an end product and by directly producing pressurized water with WECs, rather than electricity as an intermediary, it is presently only $12 \%$ greater than typical water cost in California. This study suggests that a WEC array that produces water may be a viable, near-term solution to the nation's water supply, and the niche application of the WPDS may also provide developers with new opportunities to further develop technologies that benefit both the electric and drinking

*Address all correspondence to this author. water markets.

\section{KEYWORDS}

Wave energy; desalination; reverse osmosis; time-domain numerical model; cost of energy; cost of water

\section{INTRODUCTION}

Developing alternative water resources through the use of desalination is important to human activities. But desalination technologies are inherently energy-intensive, with the majority of processes requiring high levels of electricity consumption. Further, in many areas where water is scarce, electricity prices are also high, for example, in California, or areas with limited electrical grid connection (e.g., small islands and isolated coastal communities). Thus, reverse osmosis has been the most commonly used desalination process because of the lower energy consumption than traditional thermal processes, which, among other reasons, makes reverse osmosis one of the most promising desalination approaches. However, it still requires a great amount of energy to create the pressure needed to pump the saltwater through the reverse-osmosis membranes. A wave energy converter (WEC) system has the potential to convert wave energy directly into the high-pressure flow that is needed by the reverse-osmosis system and eliminate the electricity production process to potentially reduce the cost of water. In addition, the niche application of wave-powered desalination will also provide a great opportunity to further advance wave energy technologies for both water and electricity generation.

Several designs have been proposed to develop wavepowered desalination plants in the past 30 years, e.g., a linearpump-based buoy system (Delbuoy) in the 1980s [1], an oscillat- 
ing water column type of WEC in India in 2004 [2], and more recently a fixed-bottom flapper design from Resolute Marine [3]. Folley and Whittaker $[4,5]$ looked into the potential cost of water using a wave-powered desalination system (WPDS) in United Kingdom, in which they demonstrated the economic potential for the technology.

A wave-to-water numerical model that simulates both the device hydrodynamics and reverse-osmosis process is being developed from WEC-Sim, which is a time-domain, radiation-anddiffraction-method-based numerical tool [6]. WEC-Sim has been used to simulate a wide range of WEC designs, and the simulation results have been verified and validated against those produced from other numerical models and experimental measurements. Combining the hydrodynamic model with a solutiondiffusion model to simulate the reverse-osmosis process provides a useful tool for investigating the potential water generation performance of the WPDS as well as for evaluating the sizing and loading of the components in the system.

The objective of this research is to investigate the economic potential of the WPDS in the United States, particularly in California, where electricity costs are high compared to other regions and water costs are high because of drought conditions in recent years. The paper first describes the wave-to-water modeling methods as well as the methodology and assumptions used in the techno-economic model. Next, we discuss a numerical model validation study and the simulation of an oscillating surge WEC (OSWEC) pumped reverse-osmosis desalination system and its water production performance. The predicted water production was provided to a techno-economic model to estimate the potential levelized cost of water (LCOW) using the wave resource at a reference site on the coast of northern California. The estimated LCOW was also compared to the value provided by Folley and Whittaker [5] to investigate the sensitivity of the technoeconomic assumptions used in the calculations. For comparison purposes, the study also revealed the potential cost of energy for the WEC if the device was used to generate electricity. Finally, a discussion on the comparison between the market entry price and estimated LCOW from the OSWEC is included.

\section{WAVE-POWERED DESALINATION SYSTEM}

The WPDS consists of a bottom-hinged OSWEC, a set of reverse-osmosis membranes, a pressure exchanger, and an accumulator. Figure 1 shows the schematic representation of the system, which was adopted based on the designs from Folley and Whittaker [5] and Sarai Atab et al. [7]. The OSWEC captures wave energy from the relative rotational motion between the flap and the fixed base, which also includes a set of rotaryto-linear adjustable rods for converting the wave-induced torque. This process creates the high pressure that is needed to pump seawater through the reverse-osmosis membrane for freshwater production (permeate flow). The mass properties and device dimensions for the OSWEC (in full scale) are listed in Table 1 and are based on the values from vant Hoff [8], where the top of the flap is $2.1 \mathrm{~m}$ above the mean water surface (MWS). The accumu-
TABLE 1. OSWEC MASS PROPERTIES AND DIMENSIONS

\begin{tabular}{ll}
\hline Parameters & Values (unit) \\
\hline Device width and thickness & $18 \mathrm{~m} \mathrm{x} 1.8 \mathrm{~m}$ \\
Flap height & $11 \mathrm{~m}$ \\
Base height & $2 \mathrm{~m}$ \\
Hinge depth & $8.9 \mathrm{~m}$ (from MWS) \\
Center of gravity (CG) & $3.9 \mathrm{~m}$ (from MWS) \\
Water depth & $10.9 \mathrm{~m}$ \\
Mass & $127000 \mathrm{~kg}^{6}$ \\
Moment of inertia (at CG) & $1.85 \times 10^{6} \mathrm{kgm}^{2}$ \\
\hline
\end{tabular}

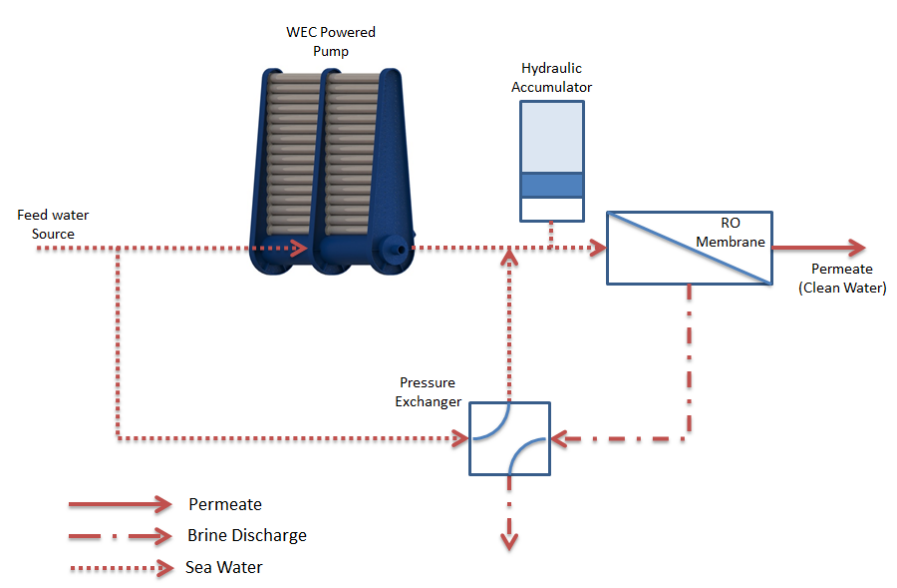

FIGURE 1. SCHEMATIC REPRESENTATION OF THE WAVEPOWERED REVERSE-OSMOSIS DESALINATION SYSTEM.

lator was used to minimize the pressure and flux fluctuation induced by the flap oscillatory motion, and the pressure exchanger (an energy recovery unit) was included to recover the energy loss from the rejected brine to pump additional seawater back to the system. Note that the WPDS presented here is a pure mechanical system, therefore we did not consider any electricity production.

\section{NUMERICAL METHODS}

The wave-to-water numerical model that simulates both the WEC hydrodynamics and reverse-osmosis process was developed based on a time-domain radiation-and-diffraction-methodbased numerical model (WEC-Sim), as shown in Fig. 2. This section will describe the numerical methods used for modeling the hydrodynamics of the WEC as well as the reverse-osmosis desalination process.

\section{WEC Hydrodynamics}

WEC-Sim is a time-domain numerical model for solving the system dynamics of WECs that consist of multiple bodies, 


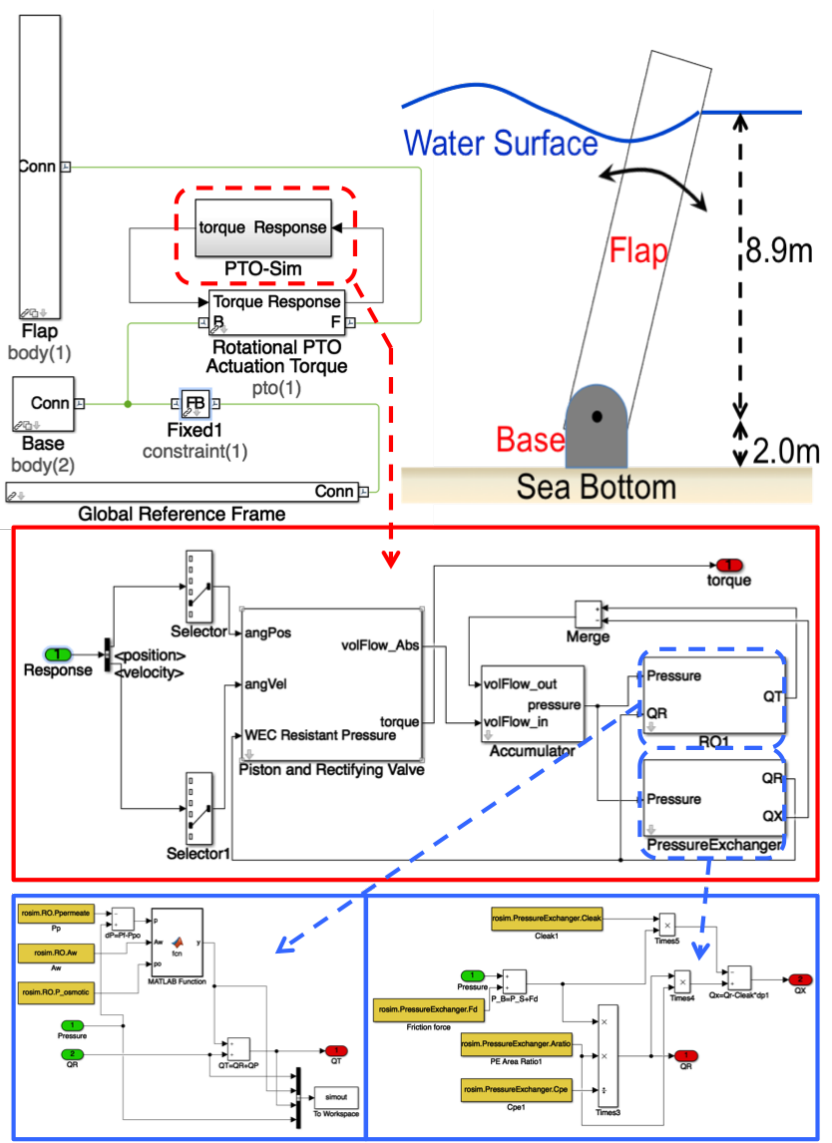

FIGURE 2. WEC-SIM AND REVERSE-OSMOSIS DESALINATION MODELS

power-take-off (PTO) systems, and mooring systems [6]. The dynamic response in WEC-Sim is calculated by solving the equation of motion for each body about its center of gravity, based on Cummins' equation [9], which can be written as:

$$
\begin{aligned}
\left(m+A_{\infty}\right) \ddot{X}= & -\int_{0}^{t} K(t-\tau) \dot{X}(\tau) d \tau \\
& +F_{\text {ext }}+F_{\text {vis }}+F_{\text {res }}+F_{P T O},
\end{aligned}
$$

where $A_{\infty}$ is the added mass matrix at infinite frequency, $X$ is the (translational and rotational) displacement vector of the body, $m$ is the mass matrix, $K$ is the impulse response function, $F_{\text {ext }}$ is the wave-excitation force, $F_{P T O}$ is the force from the PTO system, $F_{v i s}$ is the quadratic viscous damping term calculated using Morison's equation, and $F_{\text {res }}$ is the net buoyancy restoring force. In this study, we used WAMIT [10], which is a boundary-elementmethod-based frequency-domain potential flow solver, to obtain the added mass, wave excitation, impulse response function, and restoring stiffness terms.

\section{Reverse-Osmosis Desalination}

To simulate the reverse-osmosis process, which permeates saltwater through a membrane, a solution-diffusion model was developed. The model assumes the permeate flow is primarily dictated by the net driving pressure $(\Delta p)$, which is equal to the average incoming feed pressure minus the difference in osmotic pressure $(\Delta \pi)$ over the membrane [7],

$$
Q_{P}=A_{\omega}(\Delta p-\Delta \pi),
$$

where $A_{\omega}$ is the permeability coefficient, depending on the membrane permeability, membrane surface area, temperature, and fouling factor. Also based on the model, the solute concentration in permeate can be expressed as

$$
C_{p}=\frac{C_{m}}{\frac{A_{\omega}}{B_{s}}(\Delta p-\Delta \pi)+1},
$$

where $C_{m}$ is the solute concentration in the membrane (seawater side) and $B_{s}$ is the solute transport parameter.

Following the mathematical model given by [5], the pressure in and out of the pressure exchanger is given as

$$
\left(P_{B}-P_{O}\right) A_{B}-F_{d}=\left(P_{R}-P_{S}\right) A_{S},
$$

where $P_{B}, P_{O}, P_{R}$, and $P_{S}$ are the brine pressure out of the reverseosmosis membrane, pressure exchanger exhaust pressure, feed pressure to the membrane, and the pressure exchanger intake seawater pressure, respectively. $A_{S}$ and $A_{B}$ are the area of the piston on the seawater side and the brine side.

In addition, the flux conservation is preserved at the pressure exchanger,

$$
Q_{R}=Q_{B} \frac{A_{S}}{A_{B}}-C_{l}\left(P_{R}-P_{S}\right),
$$

where $Q_{R}$ is the flow feed to the reverse-osmosis membrane, $Q_{B}$ is the brine flow from the reverse-osmosis membrane, and $C_{l}$ is the leakage coefficient.

\section{ECONOMICS}

To evaluate the economic potential of the WPDS, the LCOW is used. LCOW is calculated in the same manner as the levelized cost of energy (LCOE), but instead of the denominator representing power delivered to the grid, it represents the amount of freshwater supplied. The fundamental assumptions and inputs for the economic model are described in this section.

\section{Methodology}

LCOW, just like LCOE, can be used to determine the "break even" cost for a technology, assuming a minimum rate of return. 
TABLE 2. ASSUMPTIONS FOR LCOW CALCULATIONS

\begin{tabular}{ll}
\hline Real Discount Rate & $7 \%$ \\
Inflation Rate & $2.5 \%$ \\
Composite Federal-State Tax Rate & $39.6 \%$ \\
MACRS Depreciation Schedule & 5 years \\
Economic Life & 20 years \\
\hline
\end{tabular}

MACRS: Modified Accelerated Cost Recovery System

Modifying the LCOE equation, provided by the U.S. Department of Energy (DOE) LCOE guidance for marine and hydrokinetic technologies [11], yields the following equation for LCOW:

$$
\mathrm{LCOW}=\frac{(\mathrm{FCR} \times \mathrm{CapEx})+\mathrm{OpEx}}{\mathrm{AWP}},
$$

where FCR represents a financing term known as the fixed charge rate. In this paper, the FCR uses the same set of assumptions prescribed for LCOE, yielding a value of $10.8 \%$ [11] with primary assumptions listed in Table 2. The capital expenditures (CapEx) represent the summation of all depreciable costs at year zero. This includes all costs associated with planning, design, manufacturing, deployment, and project management for the WEC array. The operational expenditures (OpEx) represent all of the fixed and variable annual expenses such as operation, maintenance, and monitoring activities, which can be simplified as nondepreciable WEC costs. Lastly, AWP represents the average annual water production delivered by the system.

\section{Economic Model Inputs}

The CapEx and OpEx estimates for the WPDS are scaled values from the DOE Marine and Hydrokinetic Reference Model 5 (RM5) design [12], which is a floating OSWEC with similar characteristics, except for the foundation. The OSWEC that was simulated in this analysis has a narrower flap width than what was designed for RM5 (18 m vs. $25 \mathrm{~m}$ ), and therefore the structural costs have been scaled linearly by a factor of 0.72 . To determine if WEC-powered desalination is feasible at scale, the 100unit array costs for the RM5 have been used instead of single unit values. Although the modeled OSWEC is of the fixed-bottom variety (as opposed to a floating system for the RM5), costs for the foundation have been assumed to be equivalent to the additional structure and mooring costs that are used for the floating RM5. Although this is a gross oversimplification, it is likely conservative being that a low-cost concrete platform could be used for a nearshore fixed-bottom device.

The PTO system was replaced by reverse-osmosis desalination units. However, necessary components critical to the reverse-osmosis unit and their associated costs were still considered in the study, including hydraulic cylinders and associated mounting, valves (relief, check, solenoids) and supporting hardware, pressure transducers, flap bearings, and assembly (10\% of
TABLE 3. CONSIDERED OPEX COST

\begin{tabular}{ll}
\hline Direct Labor Costs & $\$ 29,700 /$ laborer \\
Management Labor Costs & $\$ 66,000 /$ manager \\
Spare Parts & $\$ 0.04 / \mathrm{m}^{3}$ \\
Pretreatment & $\$ 0.03 / \mathrm{m}^{3}$ \\
Posttreatment & $\$ 0.01 / \mathrm{m}^{3}$ \\
Membranes & $\$ 0.07 / \mathrm{m}^{3}$ \\
Insurance & $0.5 \%$ of reverse-osmosis CapEx \\
\hline
\end{tabular}

PTO cost). Except for the accumulators, the PTO costs have been scaled up by $72 \%$ to account for the additional power that is associated with the fixed-bottom OSWEC (620 MW/360 MW). The accumulator costs were determined based on the actual size of the accumulator volume that was modeled in the wave-to-water model. Although the size of the accumulator is expected to influence the water production, an accumulator of $6 \mathrm{~m}^{3}$ was used in this study, which has a relatively small influence on the water production [4] and was selected to potentially allow the WPDS to operate at larger wave environment. However, further analysis on the accumulator volume and its influence on the water production and associated cost is needed.

Although the PTO costs have been simplified for the WEC, additional CapEx and OpEx costs must be included to account for the reverse-osmosis unit. For simplicity, the reverse-osmosis unit was assumed to have similar costs associated with typical large-scale reverse-osmosis facilities that were determined using the Desalination Economic Evaluation Program (DEEP 5.1) developed by the International Atomic Energy Agency [13]. The DEEP 5.1 model uses a reverse-osmosis CapEx value as a function of plant capacity of $\$ 1,177 / \mathrm{m}^{3} /$ day. The OpEx estimate depends on both capacity and produced water and generally includes the typical costs associated with membrane replacement as a result of fouling, labor costs, pretreatment, posttreatment, and other replacement costs. The OpEx for the WPDS was determined from the summation of the values listed in Table 3.

The number of laborers and managers required to operate and maintain the reverse-osmosis plant is determined using the following empirical equations:

$$
\begin{gathered}
\mathrm{N}_{\text {Laborers }}=\left(\frac{\mathrm{Cap}_{\mathrm{RO}} \times 264}{6 \times 10^{6}}\right)^{.4}+\frac{18}{1.4}, \\
\mathrm{~N}_{\text {Managers }}=\left(\frac{5+\frac{\mathrm{Cap}_{\mathrm{RO}}}{55000}}{2}\right)
\end{gathered}
$$

where $\mathrm{Cap}_{\mathrm{RO}}$ is equal to the plant capacity in $\mathrm{m}^{3} /$ day. Using the cost assumptions above, the scaled CapEx and OpEx from RM5, and the simulated value for AWP, the LCOW can be calculated. 


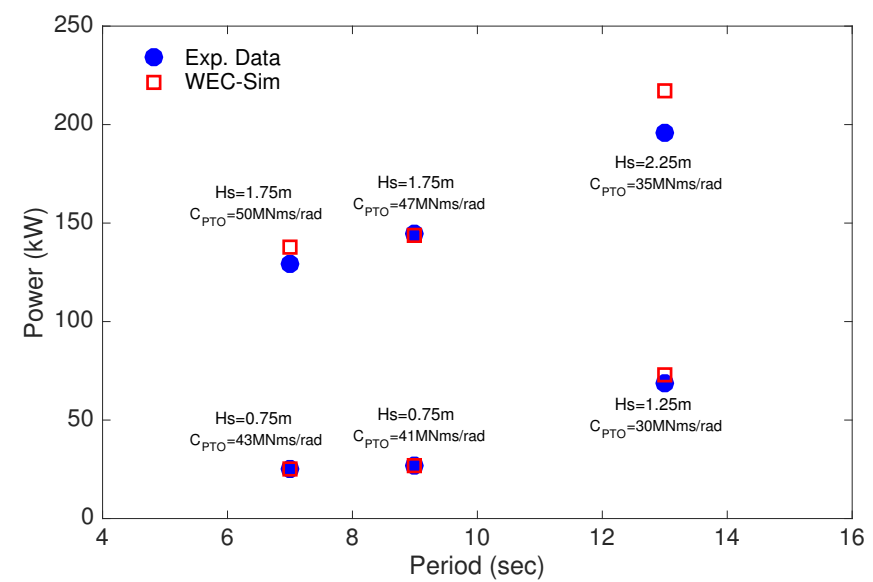

FIGURE 3. COMPARISON OF POWER PERFORMANCE FROM WEC-SIM AND VANT HOFF'S MEASUREMENTS (PRESENTED IN FULL SCALE)

\section{NUMERICAL MODEL VALIDATION}

To validate the WEC-Sim model, the OSWEC was first simulated in WEC-Sim without the rotary-to-linear adjustable rod to match experimental test settings. The predicted averaged mechanical power values were compared to the measurements from the 1/20 model-scale wave tests, reported by vant Hoff in his experimental study [8]. To account for the effect of viscosity on the WEC hydrodynamics, the flap was represented by five Morison elements in the vertical direction with a drag coefficient of $C_{d}=1$ specified for the direction normal to the flap surface. The irregular wave environments were simulated using the Bretschneider Spectrum. Each simulation was $2000 \mathrm{~s}$ long, with a ramp time of $250 \mathrm{~s}$ and a time-step size of $0.01 \mathrm{~s}$. Only the results from the last $1500 \mathrm{~s}$ were used for calculating the time-averaged power output. Figure 3 shows a comparison between the WEC-Sim results and vant Hoff's measurement data, wherein power is plotted against the energy period, Te, for various significant wave heights, Hs, and PTO damping coefficients. Overall, the WEC-Sim simulation results agreed well with those from the experimental data. ${ }^{1}$

\section{MODELING OF WAVE-POWERED REVERSE-OSMOSIS SYSTEM}

This section describes the system and model parameters used in the wave-to-water model simulations, the wave resource from a reference site, and the predicted water production.

\section{Model Setup}

The performance of the wave-powered reverse-osmosis desalination system was analyzed using the developed wave-towater numerical model, as shown in Fig. 2. The specifications for the accumulator, reverse-osmosis membrane, and the pressure exchanger are listed in Table 4. The same hydrodynamic

\footnotetext{
${ }^{1}$ A similar validation study was carried out and presented in [14] using a rotational quadratic damping coefficient for calculating the viscous damping term.
}

TABLE 4. DESALINATION MODEL SPECIFICATIONS

\begin{tabular}{lll}
\hline & Parameters & Values (unit) \\
\hline Accumulator & Volume & $6 \mathrm{~m}^{3}$ \\
\hline \multirow{2}{*}{ Reverse } & Osmotic pressure & $2275 \mathrm{kPa}$ \\
Osmosis & Target design pressure & $6900 \mathrm{kPa}$ \\
& Salinity & $35,000 \mathrm{ppm}$ \\
& Target water quality & $70 \mathrm{ppm}$ \\
\hline \multirow{2}{*}{ Pressure } & Leakage coefficient & $10^{-11} \mathrm{~m}^{3} / \mathrm{Pa} \mathrm{s}$ \\
Exchanger & Piston drag force & $100 \mathrm{~N}$ \\
& Piston diameter & $150 \mathrm{~mm}$ \\
& Area ratio & 0.95 \\
\hline
\end{tabular}

model settings as the validation study were used for calculating the time-averaged water production. Figure 4 shows an example of the time history of wave elevation, generated permeate flow rate, and the driven pressure on the seawater side of the membrane. Note that the use of the accumulator helped reduce the pressure and flow rate fluctuation. However, the peak pressure and flow rate was still around 3-4 times the averaged value as a result of the oscillations and variability of irregular wave conditions.

Moreover, we assumed the WPDS included multiple sets of valve-controlled piston cylinders and reverse-osmosis membranes. Controlling these valves adjusted the membrane permeability and the designed pressure, providing required water quality. We also assumed the concentration polarization effect on the membrane is negligible to simplify the analysis. Further, the pressure exchanger contains a control valve, represented by linear damping in the wave-to-water model, which was adjusted to keep the reverse-osmosis system recovery ratio at an average value of approximately $45 \%$. To account for the influence of the osmosis pressure on instantaneous water generation in our simple solution-diffusion model, the saltwater could be permeated through the membrane only when the wave-induced feed pressure to the reverse-osmosis membrane was larger than the osmotic pressure. Otherwise, the permeate flow went to zero and all the flows were rejected and pushed through the pressure exchanger to re-energize more fresh seawater to the accumulator.

\section{Water Production}

To evaluate the potential water production generated by deploying the WPDS in California, we used the wave resource statistic data from a reference site near Humboldt Bay, California, for the LCOW estimate. The data were obtained from the National Data Buoy Center buoy (\#46212) measurement from 2004 to 2012 [15]. Figure 5 shows the wave statistics data at the reference site, which are represented by the percentage occur- 

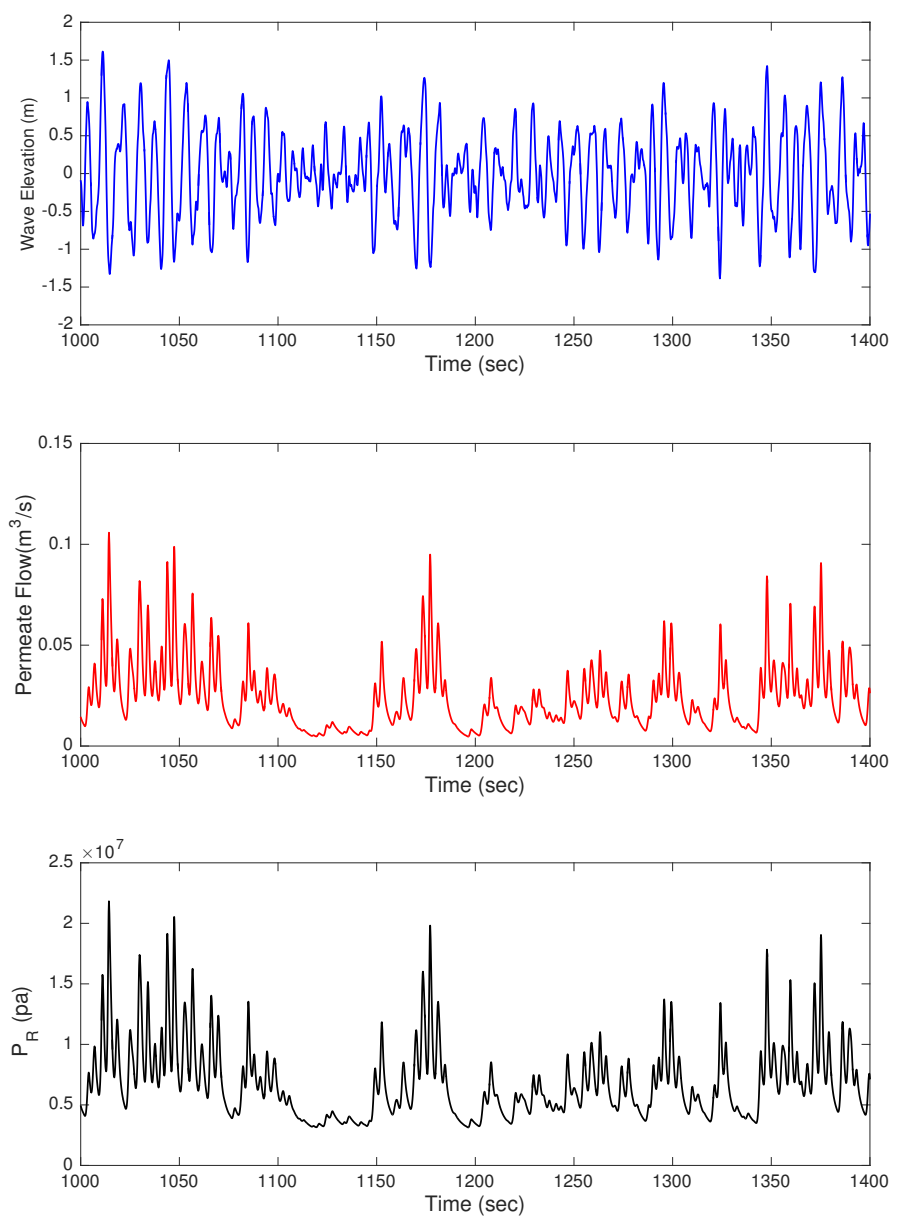

FIGURE 4. TIME HISTORY OF WAVE ELEVATION, PERMEATE FLOW RATE, AND REVERSE-OSMOSIS-MEMBRANE-DRIVEN PRESSURE FROM THE SIMULATIONS $(\mathrm{Hs}=2.25 \mathrm{~m}$ and $\mathrm{T} p=8.7 \mathrm{~s})$

rence of each binned sea state and characterized by Hs and $\mathrm{Te}^{2}$ The spectrally computed annual averaged wave density is around $30 \mathrm{~kW} / \mathrm{m}$, and this reference site has a wave climate representative of the West Coast of the United States. Although the buoy data also included the directional spectrums, only the significant wave height and peak period were used to characterize the wave resource in this study. The designed sea states are highlighted inside the red zone, which are the wave conditions that the WPDS was assumed to operate in and generate water from, and where we applied the wave-to-water numerical model to simulate the device water production.

Similar to the standard representation of WEC device power output using a power matrix, we represented the system water generation performance using a water matrix, defined by a set of binned sea states. Figure 6 plots the water matrix, which was obtained by modeling the WPDS using the wave-to-water model and calculating the averaged water production at each binned sea state. AWP was calculated by summing the product of the wave

\footnotetext{
${ }^{2}$ The cumulated total occurrence percentage is $99.8 \%$, and occurrences to annual power of less than $0.01 \%$ are not shown in the figure
}

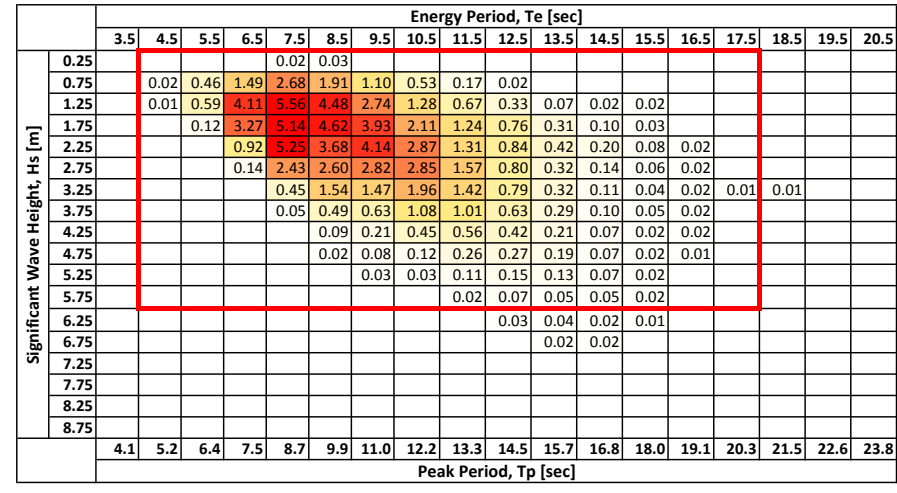

FIGURE 5. NATIONAL DATA BUOY CENTER WAVE STATISTICS DATA AT HUMBOLDT BAY, CALIFORNIA

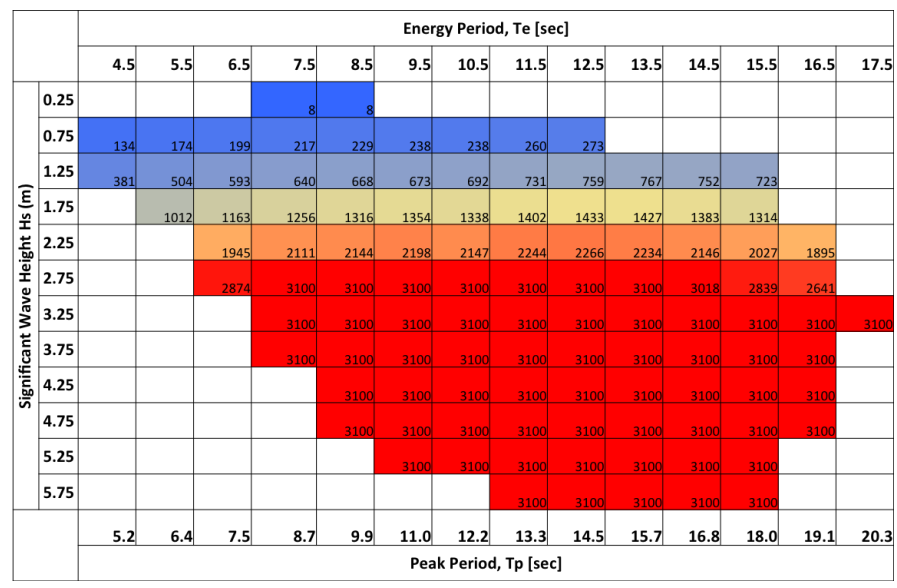

FIGURE 6. WATER MATRIX COMPUTED FROM WEC-SIM/ROSIM SIMULATIONS $\left(\mathrm{m}^{3} /\right.$ day $)$

resource statistic from the reference site (Fig. 5) and the water matrix (Fig. 6). Additional losses from maintenance-related downtime $(5 \%)$ and wave energy reduction at nearshore shallow water $(10 \%$, which was based on the study of [16]) were also considered in the AWP calculation.

Figure 7 plots the influence of rated reverse-osmosis capacity on LCOW, in which a capacity of $3100 \mathrm{~m}^{3} /$ day gives the lowest LCOW. Thus, we assumed the maximum water generation from the reverse-osmosis system was limited to $3100 \mathrm{~m}^{3} /$ day, which led to a capacity factor of $49 \%$, to reduce the size of the reverse-osmosis membrane and the overall cost of the reverseosmosis system. In addition, losses from the pressure exchanger were considered, including piston drag force, system leakage, and system efficiency (shown in Table 4).

\section{COST OF WATER IN THE UNITED STATES}

In the United States, the cost of water fluctuates because of a variety of factors, including the water source. The majority of the U.S. public water systems are supplied by groundwater [17]. As groundwater resources become harder to locate and water de- 


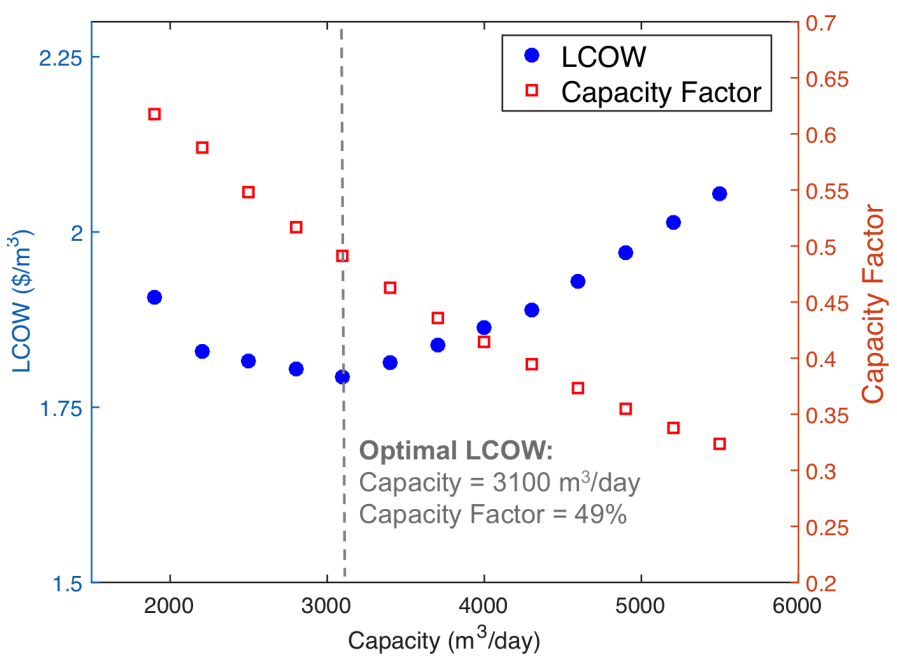

FIGURE 7. LCOW AND ASSOCIATED CAPACITY FACTOR FOR DIFFERENT WATER PRODUCTION CAPACITY

mand increases, there is a growing need for additional sources of water. As a result, seawater desalination has become an attractive option, with reverse osmosis being the most widely used form of desalination technologies [18]. The cost of desalinated seawater also varies as a result of many factors, including, but not limited to, energy costs, water salinity, and labor rates. Accounting for these factors, an end-use pricing range of $\$ 1.85-\$ 3.25 / \mathrm{m}^{3}$ [19] is typical in the United States for desalinated water. The Carlsbad seawater reverse-osmosis facility in San Diego, California, became operational in 2015 with an estimated produced cost of $\$ 1.61 / \mathrm{m}^{3}$ [20], in a region where commercial and industrial customers pay approximately $\$ 1.88 / \mathrm{m}^{3}$ and residential customers pay approximately $\$ 1.78 / \mathrm{m}^{3}$ (second-tier pricing) [21]. Therefore, for the analysis in this paper, it is assumed that an LCOW of $\$ 1.60 / \mathrm{m}^{3}$ is a conservative market entry given the current market conditions. LCOW could be evaluated using the CapEX, OpEx, and annual water production values listed in Table 5, which was calculated based on the cost assumptions described in the economics section, the simulated water matrix, and the reference site wave resource.

As shown in Table 5, the simulated system has an LCOW of $\$ 1.79 / \mathrm{m}^{3}$. To understand the cost sensitivity, the 100 -unit cost estimates were replaced with the cost estimates for a 10-unit array, and the LCOW increased to $\$ 2.89 / \mathrm{m}^{3}$ (an approximate $38 \%$ increase). The lack of sensitivity to array size, when compared with electricity generation, is a result of the reverse-osmosis CapEx costs being nearly equal to the WEC CapEx costs, and the reverse-osmosis OpEx costs being approximately $70 \%$ greater than the WEC OpEx costs, when using the 100-unit WEC cost estimates. Additionally, the single largest cost driver for reverse osmosis and electricity has been eliminated [22]. It reduces nondepreciable costs, which have a greater effect on LCOW than a reduction in depreciable costs. It is important to note, however, that the optimal LCOW is a function of reverse-osmosis capacity, annual production, and a ratio between CapEx and OpEx.
TABLE 5. LCOW INPUTS PER WEC IN CALIFORNIA, ASSUMING A 100-UNIT ARRAY

\begin{tabular}{ll}
\hline Parameters & Values (per unit) \\
\hline FCR & $10.8 \%$ \\
WEC CapEx & $\$ 3,877,896 \mathrm{USD}$ \\
WEC OpEx & $\$ 68,107 \mathrm{USD} / \mathrm{yr}$ \\
Reverse Osmosis CapEx & $\$ 3,684,700 \mathrm{USD}$ \\
Reverse Osmosis OpEx & $\$ 477,843 \mathrm{USD} / \mathrm{yr}$ \\
Reverse Osmosis Capacity & $3100 \mathrm{~m}^{3} / \mathrm{day}$ \\
Capacity Factor & $49 \%$ \\
Annual Water Production & $556,000 \mathrm{~m}^{3} / \mathrm{yr}(\mathrm{per}$ WEC) \\
\hline LCOW & $\$ 1.79 / \mathrm{m}^{3}$ \\
\hline
\end{tabular}

For this analysis, reverse-osmosis capacity was reduced to $3100 \mathrm{~m}^{3} /$ day $(49 \%$ capacity factor), from a potential capacity of $6300 \mathrm{~m}^{3} /$ day, to minimize LCOW. Analysis published by Folley and Whittaker in 2009 [5] suggested that a capacity factor of $62 \%$ yields optimal LCOW for the WEC device with the associated CapEx that they used. The variation in resource and cost assumptions contribute to the discrepancy between the two studies. Although, it is clear from the two results that limiting water production (the rated capacity of the reverse-osmosis system) is necessary for optimization because of the oscillating nature of waves as well as seasonal fluctuations.

\section{DISCUSSION}

To validate both the reverse-osmosis model and the economic inputs, we compared the results published here with the results published by Folley and Whittaker in 2009 [5]. The results of the comparative analysis are shown in Table 6. Folley and Whittaker estimated the cost of wave-powered desalination to be approximately $£ 0.45 / \mathrm{m}^{3}$. The article was received in October 2007, therefore it can be assumed that the final analysis was performed that year. In 2007, the average exchange rate between the British pound (GBP) and the U.S. dollar (USD) was 2:1 GBP to USD. Because the RM5 analysis was performed in 2014 rather than 2007, an additional 14\% increase was added to account for inflation [23]. The financial assumptions listed by Folley and Whittaker assume an $8 \%$ interest rate and a 25 -year economic life, which translates to an FCR of approximately $9.4 \%$ versus the $10.8 \%$, suggested by US Department of Energy [11].

In addition, the WEC modeled for this analysis is $18 \mathrm{~m}$ wide, compared to the 26-m-wide Oyster WEC used by Folley [24]. Therefore, the WEC CapEx costs were reduced for the comparative analysis by a factor of $69 \%(18 / 26)$. After translating from GBP to 2014 USD, Folley and Whittaker's LCOW is equivalent to $\$ 1.08 / \mathrm{m}^{3}$. Increasing the financial assumption from the $9.4 \%$ equivalent FCR to DOE's FCR of $10.8 \%$, the LCOW would in- 
TABLE 6. LCOW WHEN USING CAPACITY FACTOR AND COSTS FROM FOLLEY AND WHITTAKER'S ASSUMPTIONS

\begin{tabular}{|c|c|c|}
\hline Parameters & $\begin{array}{l}\text { OSWEC } \\
\text { in CA }\end{array}$ & $\begin{array}{l}\text { Oyster Device } \\
\text { in [5] }\end{array}$ \\
\hline WEC CapEx & $\$ 1,653,089$ USD & $\$ 2,387,795$ USD \\
\hline WEC OpEx & $\$ 21.97 \mathrm{USD} / \mathrm{m}^{3} / \mathrm{yr}$ & $\$ 31.84 \mathrm{USD} / \mathrm{m}^{3} / \mathrm{yr}$ \\
\hline RO CapEx & $\$ 1,177 \mathrm{USD} / \mathrm{m}^{3}$ & $\$ 998.38 \mathrm{USD} / \mathrm{m}^{3}$ \\
\hline RO OpEx & $\$ 46.28 \mathrm{USD} / \mathrm{m}^{3} / \mathrm{yr}$ & $\$ 41.62 \mathrm{USD} / \mathrm{m}^{3} / \mathrm{yr}$ \\
\hline RO Capacity & $1900 \mathrm{~m}^{3} /$ day & $2500 \mathrm{~m}^{3} /$ day \\
\hline Capacity Factor & $62 \%$ & $62 \%$ \\
\hline LCOW $_{\text {Folley FCR }}$ & $\$ 1.10 / \mathrm{m}^{3}$ & $\$ 1.08 / \mathrm{m}^{3}$ \\
\hline $\mathrm{LCOW}_{\text {DOE FCR }}$ & $\$ 1.22 / \mathrm{m}^{3}$ & $\$ 1.18 / \mathrm{m}^{3}$ \\
\hline
\end{tabular}

crease again to $\$ 1.18 / \mathrm{m}^{3}$. Unsurprisingly, when all of the cost assumptions are equal and the plant size is adjusted until the capacity factor is equal, the modeled LCOW is within $2 \%$. The slight variation in LCOW is likely due to a combination of wave resource, plant availability, and rounding error. The analysis suggests that there is reasonable agreement between the water production estimates from the two models. However, when using the DOE financial assumptions and the National Renewable Energy Laboratory cost estimates, there is a discrepancy of approximately $\$ 0.60 / \mathrm{m}^{3}$. The authors are not suggesting that the results presented by Folley and Whittaker are incorrect, but that additional work needs to be performed to understand the actual costs (CapEx and OpEx) for both WECs and reverse-osmosis systems. The two estimates can be used to start bounding the range of uncertainty associated with direct WEC to reverse-osmosis desalination, although this approach is not comprehensive.

On the other hand, WEC technology has been evolving, but the majority of LCOE estimates for wave energy have yet to show near-term economic potential with the exception of niche, noncommercial markets. For this reason, many wave energy developers have struggled to find funding opportunities that allow for full-scale open-water testing, which is essential for technology development. For reference purposes, the LCOE of this OSWEC was also calculated using the same wave statistics data and with additional assumptions of $80 \%$ PTO efficiency and $98 \%$ transmission efficiency. Figure 8 shows the sensitivity of LCOE and LCOW on the array size. For a 100-unit installation, the estimated LCOE is on the order of 3-6 times the current unsubsidized electricity rates in the continental United States. By changing the end product from electricity to clean water, without any further technology advancements, the LCOW for a scaled-down, nearshore OSWEC is only $12 \%$ greater than the previously stated market entry price of $\$ 1.60 / \mathrm{m}^{3}$, assuming a 100 -unit WEC array. These estimates do not account for additional energy costs related to water delivery, and therefore the actual LCOW is likely to be higher. However, it should be noted that there are markets in

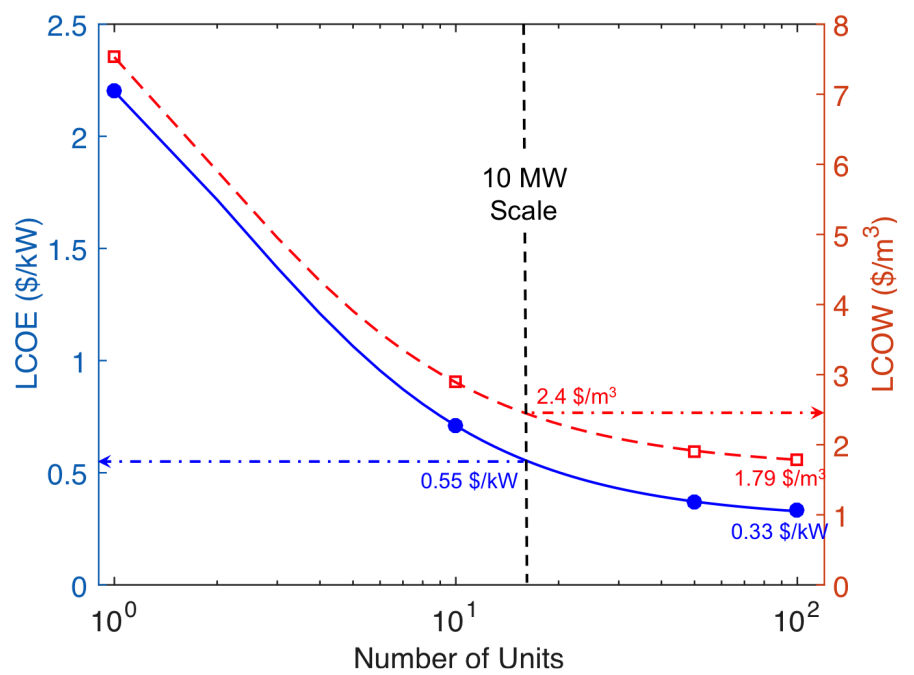

FIGURE 8. LCOE AND LCOW FOR DIFFERENT WPDS PLANT CAPACITIES (NUMBER OF UNITS)

the United States in which desalinated water has sold at prices of up to $\$ 3.25 / \mathrm{m}^{3}$, implying that WEC-powered desalination may be closer to commercial market readiness than WEC-powered electricity.

\section{CONCLUSIONS}

In the scenario evaluated, an OSWEC was directly coupled to a reverse-osmosis unit, and the levelized cost of water suggests that a WEC array producing drinking water may be a viable nearterm solution to provide the nation with drinking water. Desalination may also provide WEC developers with new opportunities to further develop technologies that benefit both the electricity and water markets. Areas such as structural and hydrodynamic designs, foundation and mooring configurations, and balance of plant will likely have significant crossover. In niche markets such as island communities, military bases, and areas with unreliable grid connections, WEC-powered desalination may provide a near-term solution that is not affected by the volatile pricing associated with diesel fuel. However, as is the case with electricgenerating WECs, future work needs to be performed to validate the model and cost assumptions associated with directly coupling a reverse-osmosis unit to a WEC. Further investigation could include studying the membrane efficiency, particularly associated with pressure oscillation and biofouling, as well as additional energy costs related to water delivery.

\section{ACKNOWLEDGMENT}

This work was supported by the U.S. Department of Energy under Contract No. DE-AC36-08GO28308 with the National Renewable Energy Laboratory. Funding for the work was provided by the DOE Office of Energy Efficiency and Renewable Energy, Wind Energy and Water Power Technologies Office. 
The U.S. Government retains and the publisher, by accepting the article for publication, acknowledges that the U.S. Government retains a nonexclusive, paid-up, irrevocable, worldwide license to publish or reproduce the published form of this work, or allow others to do so, for U.S. Government purposes.

\section{REFERENCES}

[1] Hicks, D. C., Mitcheson, G. R., Pleass, C. M., and Salevan, J. F., 1989. "Delbouy: ocean wave-powered seawater reverse osmosis desalination systems," Desalination, 73, pp. 81-94.

[2] Sharmila, N., Jalihal, P., Swamy, A., and Ravindran, M., 2004. "Wave powered desalination system," Energy, 29(11), 9, pp. 1659-1672.

[3] Resolute Marine Energy. http://www.resolutemarine.com/.

[4] Folley, M., Suarezb, B. P., and Whittaker, T., 2008. “An autonomous wave-powered desalination system," Desalination, 220, pp. 412-421.

[5] Folley, M., and Whittaker, T., 2009. "The cost of water from an autonomous wave-powered desalination plant," Renewable Energy, 34(1), pp. 75-81.

[6] Yu, Y.-H., Lawson, M., Ruehl, K., and Michelen, C., 2014. "Development and Demonstration of the WEC-Sim Wave Energy Converter Simulation Tool," In 2nd Marine Energy Technology Symposium, Seattle, WA.

[7] Sarai Atab, M., Smallbone, A., and Roskilly, A., 2016. "An operational and economic study of a reverse osmosis desalination system for potable water and land irrigation," $D e$ salination, 397, pp. 174-184.

[8] vant Hoff, J., 2009. "Hydrodynamic Modelling of the Oscillating Wave Surge Converter,", PhD thesis, The Queen's University of Belfast.

[9] Cummins, W., 1962. The Impulse Response Function and Ship Motions, David Taylor Model Dasin (DTNSRDC).

[10] Lee, C., and Newman, J., 2015. WAMITß User Manual Version 7.1.

[11] LaBonte, A., Connor, P. O., Fitzpatrick, C., Hallett, K., and Li, Y., 2013. "Standardized Cost and Performance Reporting for Marine and Hydrokinetic Technologies," In 1st Ma- rine Energy Technology Symposiumt, Washington DC.

[12] Yu, Y.-H., Jenne, D. S., Thresher, R., Copping, A., Geerlofs, S., and Hanna, L., 2015. Reference Model 5: Oscillating Surge Wave Energy Converter, National Renewable Energy Laboratory (NREL), Golden, CO.

[13] International Atomic Energy Agency, 2013. DEEP 5 User Manual.

[14] Yu, Y.-H., Li, Y., Hallett, K., and Hotimsky, C., 2014. "Design and Analysis for a Floating Oscillating Surge Wave Energy Converter," In 33rd International Conference on Ocean, Offshore and Arctic Engineering, San Francisco, CA, United States.

[15] Dallman, A. R., and Neary, V. S., 2014. Characterization of U.S. Wave Energy Converter (WEC) Test Sites: A Catalogue of Met-Ocean Data, Sandia National Laboratories, Albuquerque, NM.

[16] Folley, M., and Whittaker, T., 2009. "Analysis of the nearshore wave energy resource," Renewable Energy, 34(7), 7, pp. 1709-1715.

[17] Centers for Disease Control and Prevention. https://www.cdc.gov/.

[18] Ziolkowska, J. R., 2015. "Is Desalination Affordable? Regional Cost and Price Analysis," Water Resour Manage, pp. 1385-1397.

[19] Gude, V. G., Nirmalakhandan, N., and Deng, S., 2010. "Renewable and sustainable approaches for desalination," $R e$ newable and Sustainable Energy Reviews, 14(9), pp. 26412654.

[20] DESALDATA. https://www.desaldata.com/.

[21] The City of San Diego. Water Rates. https://www.sandiego.gov/water/rates/rates.

[22] Committee on Advancing Desalination Technology National Research Council, 2008. Desalination: A National Perspective, Washington, DC, United States.

[23] US Inflation Calculator. http://www.usinflationcalculator.com.

[24] Babarit, A., Hals, J., Kurniawan, A., Muliawan, M., Moan, T., and Krokstad, J., 2011. The NumWEC Project Selection: Numerical Estimation of Energy Delivery from a Selection of Wave Energy Converters, Trondheim, Norway. 